\title{
Correction to: Civil Engineering Applications: Specific Properties of NiTi Thick Wires and Their Damping Capabilities, A Review
}

\author{
Vicenç Torra $^{1,2} \cdot$ Ferran Martorell $^{2} \cdot$ Francisco C. Lovey $^{3} \cdot$ Marcos Leonel Sade $^{3}$
}

Published online: 8 March 2018

(c) ASM International 2018

\section{Correction to:}

Shap. Mem. Superelasticity (2017) 3:403-413 https://doi.org/10.1007/s40830-017-0135-y

We regret that a tribute, which was submitted with the original manuscript by the authors, in honor of Prof. Shuichi Miyazaki was unfortunately omitted during the publication process. The following should have been included with the published article:

Prof. Shuichi Miyazaki, we take great pleasure in our contribution of this paper on the occasion of your retirement. You have been a master for all of us with your talks and papers. You have been a friendly and sympathetic colleague, as well as an outstanding researcher.

In particular, we would like to emphasize your broad and excellent work concerning NiTi and their applications in health solutions via Ti-based alloys, overcoming the contemporary prejudgment of $\mathrm{Ni}$ as biologically incompatible.

Dear colleague, we wish you a happy retirement and a long life in the company of your relatives and friends.
The original article can be found online at https://doi.org/10.1007/ s40830-017-0135-y.

\section{Vicenç Torra}

vtorra_1@yahoo.com

1 Polytechnical University of Catalonia - Applied Physics (Retired), 08034 Barcelona, Catalonia, Spain

2 PRG, Villarroel 162, 08036 Barcelona, Catalonia, Spain

3 Centro Atomico de Bariloche, Instituto Balseiro and CONICET - Materials Physics,

8400 San Carlos de Bariloche, Rio Negro, Argentina 